\title{
EFFECTS OF YOGA PRACTICE ON LEARNING BEHAVIOUR AND ASSERTIVENESS AMONG SCHOOL CHILDREN IN TAMILNADU
}

\author{
V. YOGANANDHAN ${ }^{*}$ \\ Ph.D., Research Scholar, Centre for Yoga Studies, Annamalai University, \\ Email id:yoganaandis4@gmail.com \\ Dr. M. RAJAVELU ${ }^{2}$ \\ Assistant Professor, Department of Physical Education, Annamalai University,Annamalai \\ Nagar-608002, Tamil Nadu, India
}

\begin{abstract}
:
The purpose of the present study was to find out the effect of yoga practice on learning behaviour and assertiveness among school children of Tamilnadu. For this purpose, ninety male adolescents studying in socially backward region of Tamilnadu, with the age group of 15 to 17 years who were studying in Nandanar Boys Higher Secondary School, Chidambaram (Cuddalore District), Government Boys Higher Secondary School, Vallalapatty, Madurai (Madurai District) and Government Boys Higher Secondary School, Thiruvannamalai (Thiruvannamalai District), were chosen as subjects. They were divided into two equal groups, each group consisted of forty-five subjects, in which experimental group - I underwent yoga practice and experimental group - II acted as control that did not participate in any special activities apart from their regular curricular activities. The training period for the study was five days (Monday to Friday) a week for twelve weeks. Prior to and after the experimental period, the subjects were tested on learning behaviour and assertiveness. Learning behavior was surveyed by the Jegadheesh Srivastava learning behaviour Questionnaire and Assertiveness was surveyed by Rathu's Assertiveness inventory. The Analysis of Covariance (ANCOVA) was applied to find out any significant difference between the experimental groups and control group on selected criterion variables. The result of the study shows that the yoga practice group was significantly improved the learning behaviour and assertiveness when compared with the control group.
\end{abstract}

Key Words: learning behaviour, assertiveness, 't-test, Leven's test and ANCOVA.

\section{INTRODUCTION}

Hatha yoga activities such as asanas (postures), pranayama (breathing exercises to impact vital energies), kriyas (cleansing exercises), mudras (interval attitudes), and bandhas (neuromuscular locks) are primarily taught as physical exercises. While diverse meditational approaches work on the cerebral level, all of these practices aim to cultivate a particular degree of awareness inside oneself, which leads to changes in emotional and visceral 
functions, as well as changes in the individual's intellectual and physical functions. [1] Yoga's practices of meditation, asanas, and pranayama have a beneficial influence on stress management in teenagers. [2] The processing of sensory information at the thalamic level is aided when pranayama[3] and meditation are practiced. [4,5] Following 10 days of practice, these two practices, coupled with physical postures (asanas), cleaning practices, devotional sessions, and lectures on the theory and philosophy of yoga, increased the stability of school kids. Improved eye-hand coordination, focus, concentration, and relaxation were thought to be the reasons for the improvement[6].

A person is meant to achieve mental equanimity through practicing yoga, in which responses to pleasant or negative external circumstances are well under control, and responses are mild in intensity. [7,8]Yoga is a powerful stream of knowledge that enables practitioners to acquire radiant physical health, a calm mind, ongoing spiritual uplift, and the ability to live in harmony with others. [9]

Hatha yoga activities such as asanas (postures), pranayama (breathing exercises to impact vital energies), kriyas (cleansing exercises), mudras (interval attitudes), and bandhas (neuromuscular locks) are primarily taught as physical exercises. While diverse meditational techniques work on the cerebral level, all of these practices aim to cultivate a particular level of awareness inside oneself, which leads to changes in emotional and visceral functions, as well as changes in the individual's intellectual and physical functions. [10]

Additional studies of school-based yoga interventions also suggest positive effects of these programs on several factors such as concentration, attention, anxiety, stress, mood, resilience, emotional arousal, self-esteem, and coping frequency[11-25] however, the majority of these studies also suffer from the methodological limitations described above.

Educators, academics, and health care professionals who interact with children have long been curious about what causes academic underachievement in children of ordinary intelligence, especially when the academic challenges are not caused by physical, social, or environmental reasons. Mood disorders, emotional discomfort, peer pressures, learning disabilities, and adjustment issues are all considered to contribute to academic underachievement in children [20]. Emotional discomfort, altered cognitive functioning, and worsening in academic performance, for example, have all been suggested as possible outcomes of depressed moods brought on by peer pressures, family disputes, and having to contribute to the family's financial requirements [21]. Learning difficulties and low academic performance have also been linked to school dropout rates [22]. Mid-day lunches, for example, have failed to enhance classroom attendance [23].

\section{METHODOLOGY}

To accomplish this reason for the current examination ninety male adolescents studying in Socially Backward region of Tamilnadu, with the age group of 15 to 17 years who were studying in Nandanar Boys Higher Secondary School, Chidambaram (Cuddalore 
District), Government Boys Higher Secondary School, Vallalapatty, Madurai (Madurai District) and Government Boys Higher Secondary School, Thiruvannamalai (Thiruvannamalai District), were chosen as subjects. They were separated into two equivalent groups of forty-five subjects each. Group - I went through yoga rehearses for five days out of each week for twelve weeks and group - II went about as a control group that did not perform any physical activity.

The selected subjects were tested on learning behaviour and assertiveness prior to and following the yoga exercise program. The preparation program for the current examination was five days (Monday to Friday) out of every week for twelve weeks. The selected criterion variables such as Learning behaviour was surveyed by Jegadheesh Srivastava Learning Behaviour Questionnaire and Assertiveness was surveyed by Rathu's Assertiveness inventory. The gathered information was measurably inspected for critical contrasts if any between the experimental group and the control group, applying the 't-test. No endeavor was made to liken the groups in any way. Consequently, to adapt for contrast in the underlying methods and test the changed post-test implies huge contrasts, the Analysis of Covariance (ANCOVA) was utilized. Altogether the cases, 0.05 degree of certainty was utilized to test the importance, which was considered as proper.

\section{ANALYSIS OF DATA AND INTERPRETATION}

The data collected from the yoga practice group and control group during the pre and post-test period were statistically analyzed to examine the changes in selected learning behaviour and assertiveness of middle-aged men and the result of the study is present in the tables - I

Table - 1

PAIRED SAMPLE ' $t$ ' -TEST OF YOGA PRACTICE GROUP AND CONTROL GROUP ON SELECTED DEPENDENT VARIABLES

\begin{tabular}{|l|l|c|c|c|}
\hline \hline \multicolumn{1}{|c|}{$\begin{array}{c}\text { Name of the } \\
\text { Group }\end{array}$} & \multicolumn{1}{|c|}{$\begin{array}{c}\text { Name of the Dependent } \\
\text { Variable }\end{array}$} & $\begin{array}{c}\text { Pre-test } \\
\text { mean }\end{array}$ & $\begin{array}{c}\text { Post-test } \\
\text { mean }\end{array}$ & 't'test \\
\hline \hline $\begin{array}{l}\text { Yoga Practice } \\
\text { Group }\end{array}$ & Learning behaviour & 104.82 & 109.89 & $9.33^{*}$ \\
\cline { 2 - 5 } Control & Assertiveness & 75.31 & 8.64 & $15.136^{*}$ \\
Group & Learning behaviour & 105.29 & 104.96 & 0.66 \\
\cline { 2 - 5 } & Assertiveness & 75.38 & 75.09 & 0.619 \\
\hline \hline
\end{tabular}

*Significant at 0.05 level of confidence. The table value for the level of significance df 14 was 1.753 .

The paired sample ' $t$ ' was computed on the hatha yoga practice group and the control group factor was introduced in the above table - I. The ' $t$ ' value for learning behaviour and assertiveness for the yoga practice group were 9.33 and 15.136 respectively. The paired sample ' $t$ ' was computed on the learning behaviour and assertiveness for the control group was 0.66 and 0.619 respectively. The ' $t$ ' values for the yoga practice group are greater than 
the required table value of df 14 at 0.05 level of confidence was 1.753 . The result of the study shows that the control group did not alter significantly the performance of all the selected dependent variables.

Table -2

ANALYSIS OF COVARIANCE ON LEARNING BEHAVIOUR AND ASSERTIVENESS OF ADJUSTED POST-TEST SCORES OF EXPERIMENTAL AND CONTROL GROUPS

\begin{tabular}{|l|l|c|c|c|}
\hline \hline VariableName & \multicolumn{1}{|c|}{ Group Name } & $\begin{array}{c}\text { Yoga Practice } \\
\text { Group }\end{array}$ & Control Group & 'F'-ratio \\
\hline \hline $\begin{array}{l}\text { Learning } \\
\text { behaviour (in } \\
\text { points) }\end{array}$ & $\begin{array}{l}\text { Pre-test Mean } \pm \\
\text { S.D. }\end{array}$ & $104.82 \pm 2.51$ & $105.29 \pm 2.44$ & 0.802 \\
\cline { 2 - 5 } & $\begin{array}{l}\text { Post-test Mean } \pm \\
\text { S.D. }\end{array}$ & $109.89 \pm 2.64$ & $104.96 \pm 2.36$ & $87.24^{*}$ \\
\cline { 2 - 5 } & Adj. Post-test Mean & 110.16 & 104.85 & $294.47^{*}$ \\
\hline \multirow{2}{*}{$\begin{array}{l}\text { Assertiveness (in } \\
\text { points) }\end{array}$} & $\begin{array}{l}\text { Pre-test Mean } \pm \\
\text { S.D. }\end{array}$ & $75.31 \pm 1.65$ & $75.38 \pm 1.71$ & 0.034 \\
\cline { 2 - 5 } & $\begin{array}{l}\text { Post-test Mean } \pm \\
\text { S.D. }\end{array}$ & $78.64 \pm 1.91$ & $75.09 \pm 1.55$ & $94.12^{*}$ \\
\cline { 2 - 5 } & Adj. Post-test Mean & 78.671 & 75.063 & $246.38^{*}$ \\
\hline \hline
\end{tabular}

* Significant .05 level of confidence. (The table values required for significance at .05 level of confidence with $d f 1$ and 88 and 1 and 87 were 4.01 and 3.98 respectively).

\section{RESULTS OF THE STUDY}

Table -2 shows that the pre-test means ' $F$ ' - ratio of yoga practice and control groups on learning behaviour was 0.802 for pre-test scores is less than the required table value of 4.01 for significant at 0.05 level of confidence with df 1 and 88 . The post- and adjusted posttest mean ' $F$ ' ratio on learning behaviour was 87.24 and 294.47 was greater than the required table value of 4.01 and 3.98 for significance. The above table shows that the pre-test means ' $F$ ' ratio of yoga practice groups and control group on assertiveness was 0.034 which was less than the required table value of 4.01 for significant at 0.05 level of confidence with df 1 and 88. The post- and adjusted test ' $F$ ' ratio of yoga practice groups and control group on anxiety are 94.12 and 246.38 which was greater than the required table value of 4.01 and 3.98 for significance.The data on learning behaviour and Assertiveness of participants is graphically represented in figure I and II. 


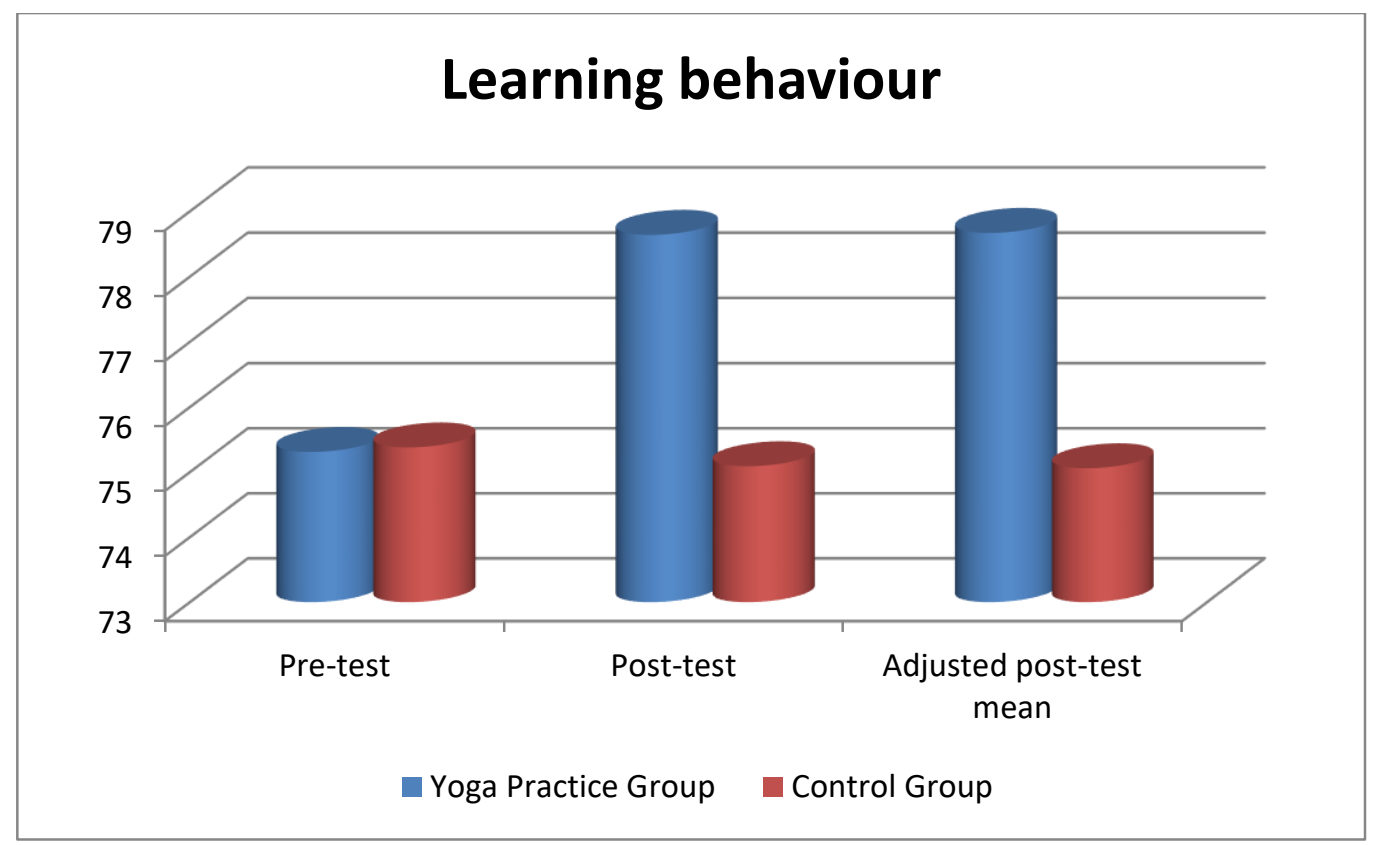

Figure-I: bar diagram showing the mean value of yoga practice group and control group on learning behaviour.

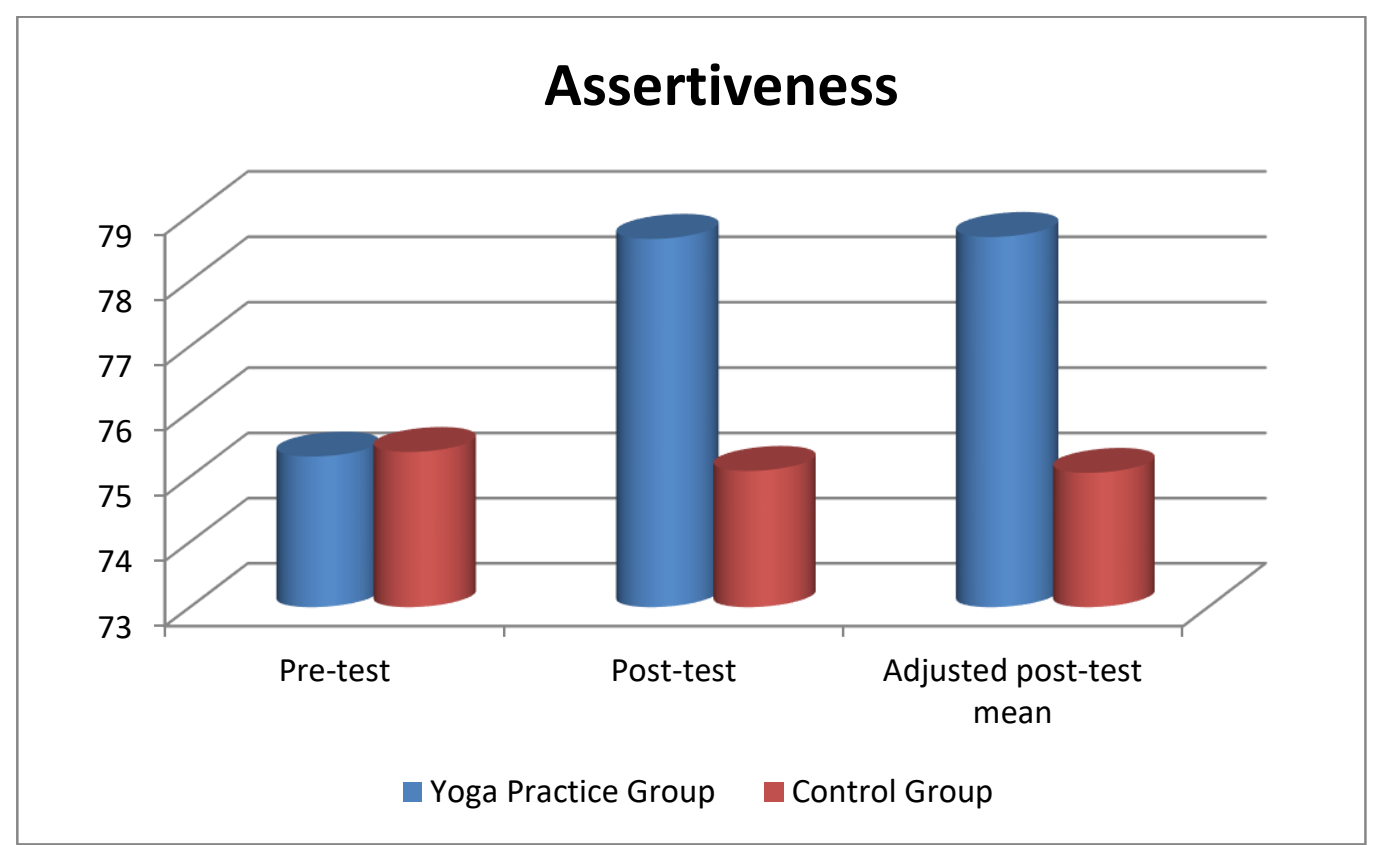

Figure-II: bar diagram showing the mean value of yoga practice group and control group on assertiveness.

\section{DISCUSSION}

The result of the study also shows that there was a significant improvement in learning behaviour and assertiveness among male adolescent socially backward students from Tamilnadu State, India. Shashi, Mohan, and Shaker[24] suggest that after practicing yoga there was significant management the anxiety and concentration due to personality development, higher concentration, and reduction of distraction thoughts (mind wandering) due to yoga training. Other researchers found that Transcendental Meditation improves 
academic performance and enhances problem-solving ability[25-29] Yoga/mindfulness activities may facilitate stress management among elementary school students and may be added as a complement to social and emotional learning activities.[30]

\section{Reference:}

1. Bhole, M. V. (1977). Psycho-Physiological importance of some yoga practices Paper presented at the international seminar on stress in Health and Diseases. Varanasi: Banaras Hindu University.

2. Krejci, M. (1994). Positive influence of yoga exercises for the Adolescents' Medicine. Mind and Adolescence, 8(2).

3. Telles, S., Joseph, C., Venkatesh, S., \& Desiraju, T. (1993). Alterations of auditory middle latency evoked potentials during yogic consciously regulated breathing and attentive state of mind. International journal of psychophysiology, 14(3), 189-198.

4. Telles, S., \& Desiraju, T. (1993). Recording of auditory middle latency evoked potentials during the practice of meditation with the syllable'OM'. The Indian journal of medical research, 98, 237-239.

5. Telles, S., Hanwnanthaiah, B. H., Nagarathna, R., \& Nagendra, H. R. (1994). Plasticity of motor control systems demonstrated by yoga training. Indian journal of physiology and pharmacology, 38, 143-143.

6. Telles, S., Nagarathna, R., Vani, P. R., \& Nagendra, H. R. (1997). A combination of focusing and defocusing through yoga reduces optical illusion more than focusing alone. Indian journal of physiology and pharmacology, 41(2), 179-182.

7. Sailer, H. R., Schlacter, J., \& Edwards, M. R. (1982). Stress: causes, consequences, and coping strategies. Personnel, 59(4), 35-48.

8. Nagendra HR, Nagarathna R.( 1977). New Perspective in stress management. Bangalore, India: Vivekananda Kendra Parkashana;

9. Tamini LK. (1961). The science of yoga. Madras, India: The Theosophical Publishing House;

10.Maharishi Mahesh Yogi.(1972) The Science and Art of living. Los Angeles. New York: International SRM Publications;

11. Bothe, D. A., Grignon, J. B., \& Olness, K. N. (2014). The effects of a stress management intervention in elementary school children. Journal of Developmental \& Behavioral Pediatrics, 35(1), 62-67.

12. Case-Smith, J., Shupe Sines, J., \& Klatt, M. (2010). Perceptions of children who participated in a school-based yoga program. Journal of Occupational Therapy, Schools, \& Early Intervention, 3(3), 226-238.

13. Conboy, L. A., Noggle, J. J., Frey, J. L., Kudesia, R. S., \& Khalsa, S. B. S. (2013). Qualitative evaluation of a high school yoga program: feasibility and perceived benefits. Explore, 9(3), 171-180.

14. Ehud, M., An, B. D., \& Avshalom, S. (2010). Here and now: Yoga in Israeli schools. International Journal of Yoga, 3(2), 42.

15. Khalsa, S. B. S., Hickey-Schultz, L., Cohen, D., Steiner, N., \& Cope, S. (2012). Evaluation of the mental health benefits of yoga in a secondary school: A preliminary 
randomized controlled trial. The journal of behavioral health services \& research, 39(1), 8090.

16. Klatt, M., Harpster, K., Browne, E., White, S., \& Case-Smith, J. (2013). Feasibility and preliminary outcomes for move-into-learning: an arts-based mindfulness classroom intervention. The Journal of Positive Psychology, 8(3), 233-241.

17. Noggle, J. J., Steiner, N. J., Minami, T., \& Khalsa, S. B. S. (2012). Benefits of yoga for psychosocial well-being in a US high school curriculum: a preliminary randomized controlled trial. Journal of Developmental \& Behavioral Pediatrics, 33(3), 193-201.

18. Mendelson, T., Greenberg, M. T., Dariotis, J. K., Gould, L. F., Rhoades, B. L., \& Leaf, P. J. (2010). Feasibility and preliminary outcomes of a school-based mindfulness intervention for urban youth. Journal of abnormal child psychology, 38(7), 985-994.

19. White, L. S. (2012). Reducing stress in school-age girls through mindful yoga. Journal of Pediatric Health Care, 26(1), 45-56.

20. Krejci, M. (1994). Positive influence of yoga exercises for the Adolescents' Medicine. Mind and Adolescence, 8(2).

21. Telles, S., Joseph, C., Venkatesh, S., \& Desiraju, T. (1993). Alterations of auditory middle latency evoked potentials during yogic consciously regulated breathing and attentive state of mind. International journal of psychophysiology, 14(3), 189-198.

22. Telles, S., \& Desiraju, T. (1993). Recording of auditory middle latency evoked potentials during the practice of meditation with the syllable'OM'. The Indian journal of medical research, 98, 237-239.

23. Telles, S., Hanumanthaiah, B., Nagarathna, R., \& Nagendra, H. R. (1993). Improvement in static motor performance following yogic training of school children. Perceptual and Motor Skills, 76(3_suppl), 1264-1266.

24. Telles, S., Nagarathna, R., Vani, P. R., \& Nagendra, H. R. (1997). A combination of focusing and defocusing through yoga reduces optical illusion more than focusing alone. Indian journal of physiology and pharmacology, 41(2), 179-182.

25. Telles, S., Joseph, C., Venkatesh, S., \& Desiraju, T. (1993). Alterations of auditory middle latency evoked potentials during yogic consciously regulated breathing and attentive state of mind. International journal of psychophysiology, 14(3), 189-198.

26. Telles, S., \& Desiraju, T. (1993). Recording of auditory middle latency evoked potentials during the practice of meditation with the syllable'OM'. The Indian journal of medical research, 98, 237-239.

27. Telles, S., Hanwnanthaiah, B. H., Nagarathna, R., \& Nagendra, H. R. (1994). Plasticity of motor control systems demonstrated by yoga training. Indian journal of physiology and pharmacology, 38, 143-143.

28. Telles, S., Nagarathna, R., Vani, P. R., \& Nagendra, H. R. (1997). A combination of focusing and defocusing through yoga reduces optical illusion more than focusing alone. Indian journal of physiology and pharmacology, 41(2), 179-182.

29. Karande, S., \& Kulkarni, M. (2005). Poor school performance. The Indian Journal of Pediatrics, 72(11), 961-967.

30. Sahasi, G., Mohan, D., \& Kacker, C. (1989). Effectiveness of yogic techniques in the management of anxiety. Journal of Personality and Clinical Studies. 